\begin{tabular}{|c|c|}
\hline & $\begin{array}{l}\text { International Journal of Trend in Scientific } \\
\text { Research and Development (IJTSRD) }\end{array}$ \\
\hline 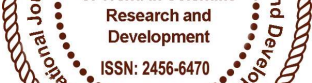 & International Open Access Journal \\
\hline 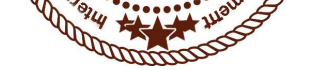 & ISSN No: 2456 - 6470 | www.ijtsrd.com | Volume - 2 | Issue - 2 \\
\hline
\end{tabular}

\title{
Corrosion Characterization of Aluminium 2024 Metal Matrix Composites Reinforced with Fly Ash in Potassium Chloride Medium
}

\author{
R. Lakshmi \\ Dr. H. R. Radha \\ Research Scholar, Dept. of Chemistry, \\ Bharathiar University, Coimbatore, India \\ Professor of Chemistry, T.John Institute \\ of Technology, Bangalore, India \\ Dr. P. V. Krupakara \\ Vice Principal, Adarsha Institute of \\ Technology, Bangalore, India \\ Latha. V \\ Assistant Professor of Chemistry, T.John Institute \\ of Technology, Bangalore, India
}

\section{ABSTRACT}

The present paper deals with the static weight loss corrosion studies of Aluminium 2024 metal matrix composites reinforced with fly ash particulates in comparison with matrix alloy using different concentrations of potassium chloride solution. Matrix alloy used in Aluminium 2024 and there inforcement used was fly ash particulates. Composites are prepared by liquid melt metallurgy technique method. Fly ash particulates are reinforced by $2,4,6$ percent by weight under dry conditions. Specimens are prepared according to ASTM standards. Both metal matrix composites and corresponding base alloys were subjected to identical test conditions to understand the influence of there inforcement on alloy with respect to corrosion behaviour and effective corrosion control. Composites show less prone to corrosion and pit formation than the matrix alloy, which may be due to chemically inertflyash particles present in the metal matrix composites. On the other hand the test also reveals that corrosion resistance of both alloy and composites increase with increase in exposure time in all concentrations of potassium chloride solution, which may be due to formation of a passive layer on the surfaces of matrix alloy and composites. Corrosion of metal matrix can be effectively controlled by converting the min to composites by the addition of inertand ceramic materials like flyash particulates. If any automobile parts like bearing are made using these composites corrosion control properties can be implemented so that they can be used effectively for a long period.

Keywords: Aluminium2024; Fly ash; particulates; vortex method

\section{INTRODUCTION}

Designers get many benefits in designing the components for automobile and aircraft industry through metal matrix composites (MMCs). These materials maintain good tensile strength at high temperature, dimensional stability, good structural rigidity and light in weight [1-5]. The safe usage of the MMC parts in the automobile engine which work particularly at high temperature and pressure environments is increased now a day's [6,7]. For the last two decades particles reinforced MMCs has been the most popular.

Among the MMCs ceramic reinforces aluminium MMCs have most popular families. Although matrix material incorporated with the second phase can enhance the physical and mechanical properties of the base metal, it could also significantly change the corrosion character. 
Particle reinforced aluminium MMCs find effective application in several thermal, automobile engines especially drives hafts, cylinders, pistons, cylinders and brake rotors. MMCs used a thigh temperature should possess good mechanical properties and resistance towards chemical degradation [8] in air and acidic environments. For high temperature applications one should have a thorough understanding about the corrosion behavior of the aluminum metal matrix composites. Some research data [9-11] indicate that the addition of $\mathrm{SiC}$ particulate do not appear to affect corrosion on some aluminium alloys because, pits were found to be more on the composite, although they were comparatively smaller and shallower than those on reinforced alloy. Gonzalez et.Al [12] have reported that the fly ash particles do not give rise to significant galvanic corrosion and no active phases are formed at the matrix/particle inter phase.

The objective of the present investigation is to develop simplified methodology and approach to study the weight loss corrosion behavior of aluminum 2024 alloy reinforced with fly ash at room temperature using sea water as corrosion medium.

\section{EXPERIMENTAL PROCEDURE}

\section{A. Material Selection}

The matrix alloy selected is A12024 and its composition is given in Table 1.

Table1: Composition of A12024

\begin{tabular}{|l|l|}
\hline $\mathrm{Cu}$ & $4.4 \%$ \\
\hline $\mathrm{Mg}$ & $1.5 \%$ \\
\hline $\mathrm{Mn}$ & $0.6 \%$ \\
\hline $\mathrm{Fe}$ & $0.25 \%$ \\
\hline $\mathrm{Si}$ & $0.25 \%$ \\
\hline $\mathrm{Zn}$ & $0.125 \%$ \\
\hline $\mathrm{Zr}$ & $0.1 \%$ \\
\hline $\mathrm{Ti}$ & $0.15 \%$ \\
\hline $\mathrm{Cr}$ & $0.15 \%$ \\
\hline $\mathrm{Al}$ & Balance \\
\hline
\end{tabular}

There inforcement selected is fly ash which is a product obtained after the burning of coal in thermal power stations. It is procured from Raichur Thermal Power station, Shaktinagar, Raichur District, Karnataka.

The corrosion medium is $0.035,0.35$ and 3.5 percent solution of potassium chloride.

\section{B. Composite preparation}

The MMCs are prepared by liquid melt metallurgy method [13]. Metal matrix alloy is heated to its liquids temperature and alumina coated with mechanical impeller is dipped and a vortex is created. The coating with impeller is necessary in order to prevent ferrousions migration from the impeller in to the melt. Preheated fly ash particles are added into the melt. The melt is thoroughly stirred and degasifying tablets made up of hexachloro ethylene is added to degasify and poured into preheated split type moulds [14]. Matrix composites containing 2, 4 and $6 \%$ of fly ash are prepared.

\section{Corrosion studies}

Weight loss corrosion studies are conducted for the above prepared samples in potassium chloride of different concentration at room temperature using weight loss method according to ASTM 69-80. The tests are conducted upto 96 hours at twenty four hours time intervals. Sixteen numbersof $250 \mathrm{~cm}^{3}$ glass beakers are taken all are filled with $200 \mathrm{~cm}^{3}$ of $0.035 \%$ potassium chloride solution. The dimensions like diameter and height of the specimens are measured using verniercaliper and the samples are weighed using digital balance. They are immersed in $0.035 \%$ potassium chloride solution and taken out at twenty four hours of intervals upto 96 hours. Then the samples are dipped in Clarke's solution and gently rubbed with a brush to remove the corrosion product, finally washed with distilled water and acetone then air dried. Weights of the corroded samples are determined, weight loss is calculated and the corrosion rate is expressed in mpy [15].

\section{RESULTS AND DISCUSSIONS}

\section{A. Microscopy}

Micro structure of as cast matrix and 6\% fly ash composite are shown in the figures 1 and 2 respectively. The polished specimens of both the above samples are etched with Keller's reagent and microstructures are taken. The microstructure of the composites how's the uniform distribution of the reinforcement with good bonding between matrix alloy and reinforcement. 


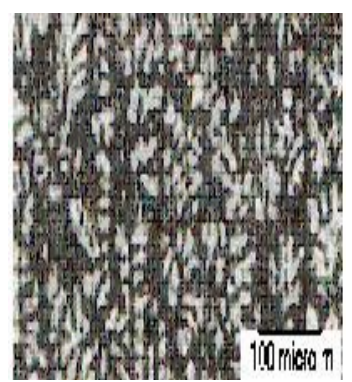

Fig.1: Microstructure Fig.2: Microstructure of matrix

6\%Composite

\section{B. Corrosion test Result}

Figures 3 - 5 show the weight loss corrosion rate of matrix and composites in different concentrations of potassium chloride solutions. The corrosion rate decreases with increase in exposure time irrespective of matrix and percentage of reinforcement. The rate of corrosion decreases as there is increase in the reinforcement content in all solutions of potassium chloride.

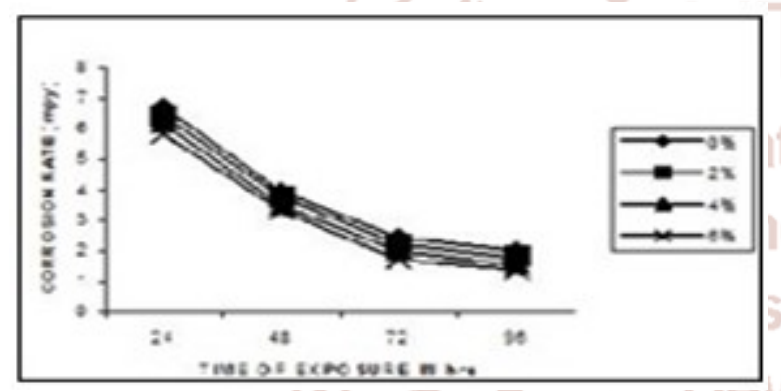

Fig 3: Weight loss corrosion $0.035 \% \mathrm{KCl}$ solution

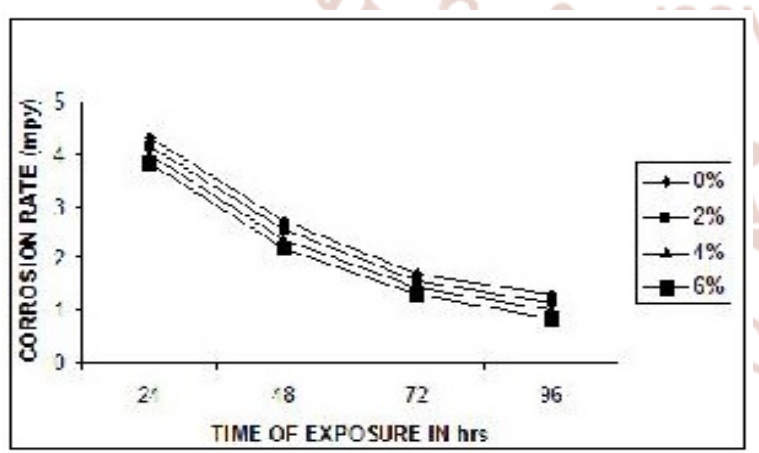

Fig. 4: Weight loss corrosion $0.35 \% \mathrm{KClsolution}$

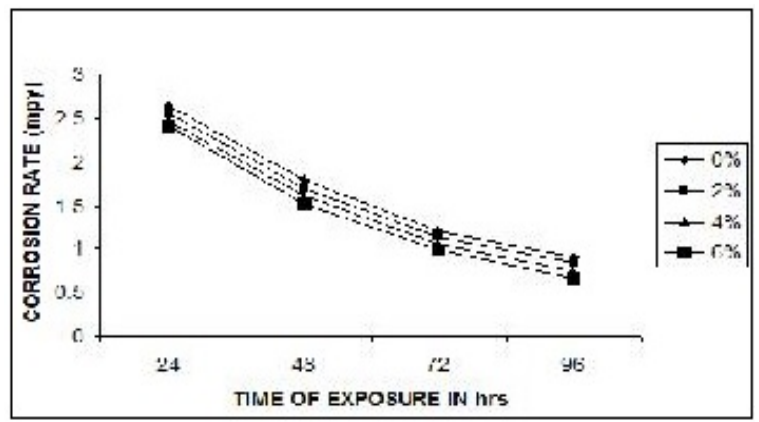

Fig. 5: Weight loss corrosion 3.50\% KClsolution

\section{Discussions}

The corrosion product formed on the surface of the composites was removed carefully and subjected to analysis and found to be made up of oxide of aluminum formed due to reaction of the matrix with potassium chloride. Due to the nonporous oxide layer of the aluminum the rate of corrosion decreases gradually.

Fly ash particles are inert and will not affect the coercion mechanism of the metal matrix composite. The results indicate that as the percentage of fly ash increases, corrosion rate decreases. This shows that the corrosion rate is directly or indirectly affects the corrosion property of the composites. Many research data show similar results when a matrix alloy is reinforced with ceramic particulates also[16].

Wu.Jinaxin et.al[17]. state that the particulates reinforced definitely play a role as barrier in corrosion properties. A particle acts as relatively physical barrier to the initiation of corrosion pits and also modifies the microstructure of the metal matrix material and hence reduces the rate of corrosion. Rodrigues[18] states that the base matrix and the reinforcement inter phase is the weakest part of the particulate reinforced composite. Hence in the corrosion process the nature of the bond whether weak or strong is critical.

\section{CONCLUSIONS}

$>$ Metal matrix composites Al2024 / fly ash composites are prepared by liquid melt metallurgy method.

MMC's are subjected to weight loss corrosion test in different concentrated solutions of potassium chloride.

The corrosion rate of composites decrease win increase in exposure time with $\mathrm{KCl}$.

$>$ The corrosion rate of composites decrease with increase in percentage of reinforcement fly ash.

$>$ The extent of corrosion damage decreased with increasing reinforcement which may be due to increase in bonding strength.

$>$ Loss of Material from corrosion was significantly high in matrix alloy with respect to metal matrix composites. 
International Journal of Trend in Scientific Research and Development (IJTSRD) ISSN: 2456-6470

\section{APPLICATIONS}

Due to its high strength and fatigue resistance, A12024 is widely used in aircraft structures, especially wing and fuselage structures under stress. Additionally, since the material is susceptible to thermal shock, Al2024 is used in qualification of liquid penetrant tests above normal temperature ranges

A12024 is typically used in connectors, rivets, hydraulic valve bodies and miscellaneous structural applications.

$>$ It is commonly used in the manufacture of truck wheels, screw machine products, scientific instruments, veterinary and orthopedic braces and equipment.

$>$ metallurgy composites for cylinder liners", Metal matrix composites, Library of congress catalog card number 93-87522, Society of Automotive Engines,Inc, 1994,pp55-64.

\section{REFERENCES}

1. B.M.Girish et.al. "Fractography, Fluidity and tensile properties of aluminium/Haematite particle composite", Journal of Mateials Engineering and performance, vol. 8(3), 1999, pp309-314

2. B.M.Satish et.al. "Effect of short glass fibers on the mechanical properties of cast ZA-27 alloy composites", Material and Design, vol. 17(5/6) 1996, pp245-250.

3. P. Reynaud "Cyclic fatigue ceramic-matrix composites at ambient and elevated temperatures". Composite Science and Technology, vol.56, 1996, pp809-814

4. S.C.T jong \& Z.Y.Ma, "The high temperature creep behavior of aluminium matrix composite reinforced with $\mathrm{SiC}, \mathrm{A} 12 \mathrm{O} 3$ and $\mathrm{TiB} 2$ particles", Composite Science and Technology, vol.57,1997pp697-702.

5. H.Akubulut,M. Durman andF.Yilnaaz,"Higher temperature Young's Modulus of aluminium shore fire reinforced Al-Si MMCs produced by liquid infilteration", Materials Science and Technology,vol.14,pp299-305.

6. E. Koya, Y.Hagiwara, S.Miura, T.Hayashi, T.Fujiwara, M. Oneda,"Developmentofaluminium powder[7]M K Aghajanjan, G.C. Atland, P.BaronAntolin, A. S. Nagelberg, "Fabrication and properties of metal matrix composites for automotive brake calipers applications", Metal matrix Composites, Library of congress catalog card number 93-87522, Society of Automotive Engines,Inc, 1994,pp77-81

7. S.H.J.Lo, S. Dionne, M.Sahoo and H.M.Hatrone, J.of. Mater. Sci.27,5681-5691(1992)

8. P.P. Trzaskoma,Corrosion.46(5)(1990)402-409.

9. Wu. Jianxin,LiuWeiLiPengXing\&Wurenjie, Jr.of Mat. Sci, let.12, (1993), 1500-1501.

10. E. L. Rodrieguex, Jr. of Mat. Sci, let, 6(1987) 718720

11. M.A.Gonzalez-nunez, C.A. Nupez-Lopez, Corrosion Sci. 37(11) (1995) 1763-1772

12. P. V.Krupakara, proceedings of "Corrosion Conference 2002" (CORCON2002)

13. Rathnakarkamath, Hiroshi Asanuma, Tribology International 31[4](1998) 188-189

14. K.H. W.Seahand J. Hemanth, Mater. Design, 15(3) 299-304

15. V. T. Vijayalakshmi and A. Ramesh, Proceedings of the Third International Conference on Advance Composites (ADCOMP2000) 2 501509

16. Wu Jinaxin, LieuliPeng Zing WuRenzie, Jr. J. Mater.Sci.Lett 12 (1993) 1500-1501

17. E.L.Rodriguez， J.Mater.Sci.Lett.6 (1987) 718720 